\title{
Genetic Counseling for Autism Spectrum Disorder in an Evolving Theoretical Landscape
}

\author{
Brenda Finucane $^{1} \cdot$ Scott M. Myers ${ }^{1}$
}

Published online: 24 June 2016

(C) The Author(s) 2016. This article is published with open access at Springerlink.com

\begin{abstract}
Purpose of Review Psychiatry is steadily moving toward a new conceptualization of brain disorders that blurs longheld diagnostic distinctions among neurodevelopmental and psychiatric conditions, including autism. Genomic discoveries are driving these changing perceptions, yet there has so far been minimal impact on traditional genetic counseling practices that continue to view autism through the lens of a dichotomous, all-or-none risk model.

Recent Findings High rates of comorbidity exist across autism spectrum disorder, schizophrenia, intellectual disability, and other brain-based disorders. Recent epidemiological studies have shown that co-occurrence of neurodevelopmental and psychiatric disorders is the rule, rather than the exception, in affected individuals and within families. Moreover, studies of chromosomal microarray analysis and whole exome sequencing have now detected many of the same pathogenic copy number and sequencelevel variants across cohorts with different clinical presentations.

Summary Going forward, the genetic counseling field will need to significantly adapt its approaches to pedigree interpretation, variant analysis, and patient education to more precisely describe both the chance and the nature of
\end{abstract}

This article is part of the Topical collection on Genetic Counseling and Clinical Testing.

Brenda Finucane

bmfinucane@geisinger.edu

Scott M. Myers

smyers1@geisinger.edu

1 Autism \& Developmental Medicine Institute, Geisinger Health System, 120 Hamm Drive, Ste 2A, Lewisburg, PA 17837, USA autism recurrence in terms of a continuum of brain dysfunction. These efforts will have implications for multiple practice areas and require philosophical changes for experienced practitioners and for the training of new genetic counselors. Resetting entrenched dichotomous notions about autism and other brain-based manifestations of genetic conditions will require a strategic educational effort on the part of the genetic counseling profession.

Keywords Autism spectrum disorder - Genetic counseling · Schizophrenia - Intellectual disability · Copy number . Pathogenic variant $\cdot$ Chromosomal microarray $\cdot$ Whole exome sequencing

The "genetics of autism" is thus neither singular nor separable from the "genetics of intellectual disability," the "genetics of schizophrenia," or the "genetics of epilepsy." The more general term of "developmental brain dysfunction" has been proposed to encompass disorders arising from altered neural development, which can manifest clinically in diverse ways.

Kevin J. Mitchell

(The Genetics of Neurodevelopmental Disorders, 2015) [1]

\section{Introduction}

When first described as a childhood-onset psychiatric condition over 70 years ago, autism was considered a rare disorder of unknown etiology. Leo Kanner originally reported on 11 children with communication disturbances, a relative lack of motivation for social and emotional interaction, and preference for an excessive degree of routine and "sameness" in their environments [2]. Over the next few decades, autism was widely regarded as a type of childhood schizophrenia (SCZ), and some theorized that it was a form of psychotic withdrawal in response to an 
emotionally cold and distant mother [3•]. By the 1970s, a more enlightened understanding of autism as a biologically based condition began to emerge. Recent decades have seen the refinement of diagnostic criteria for autism, as well as the parsing out and later recombining of autism subtypes under the current umbrella of autism spectrum disorder (ASD) $[3 \bullet, 4,5]$.

ASD is a complex, chronic neurodevelopmental disorder that is clinically and etiologically heterogeneous, yet highly heritable, with a recent meta-analysis of twin studies suggesting heritability estimates from 64 to $91 \%$ [6]. The genetic architecture of ASD includes rare pathogenic copy number variants (CNVs) and single nucleotide variants (SNVs), in addition to inherited background polygenic risk [7-9]. By a ratio of $\sim 4.5$ to 1 , boys are more commonly affected by ASD than girls, leading to speculation about female protective effects as well as genetically conferred male vulnerabilities $[10-14,15 \bullet]$.

The much publicized increase in ASD prevalence over the past three decades has been well-documented in public health surveillance studies, with the most recent large-scale report showing a steady rate of ASD of 1 in 68 children in the US between 2010 and 2012 [16]. The extent to which there has been a true increase in ASD incidence, versus the collective effects of diagnostic and ascertainment changes, continues to be debated [17-20]. There is substantial evidence that non-etiological factors, such as "diagnostic substitution" [i.e., intellectual disability (ID) diagnoses decreased at the same time ASD diagnoses increased], have played a role. However, not all of the "autism epidemic" can be explained by these factors, and research efforts continue to investigate genetic, environmental, and other potential contributors [17-22].

Deliberations about clinical diagnostic criteria for ASD have largely played out within the fields of pediatric psychiatry and psychology, with relatively little cross-fertilization from research efforts to uncover its biological basis. Recent genomic evidence has shed new light on the interconnectedness of many brain-based pediatric and adult-onset psychiatric conditions, including ASD, ID, and SCZ, at the same time revealing biological inconsistencies with clinical diagnoses defined by psychiatry's Diagnostic and Statistical Manual of Mental Disorders (DSM) [4]. The discovery of linked genetic underpinnings among several DSM-based conditions has led to emerging new perspectives on diagnosis, interventions, and research strategies for ASD [23, 24•, 25•]. This evolving conceptualization of autism as one constellation of symptoms within a larger universe of interconnected brain dysfunction has the potential to radically change genetic counseling for neurodevelopmental and psychiatric disorders.

\section{Autism as Developmental Brain Dysfunction (DBD)}

Recently, the long-standing practice of defining ASD and other psychiatric diagnoses based on dichotomous, all-ornone symptom constellations (e.g., autism vs. no autism) has been called into question $[23,24 \bullet, 26]$. Some individuals exhibit behavioral features of autism, for example, without fully meeting the criteria for an ASD diagnosis. Moreover, high rates of comorbidity exist across ASD, SCZ, ID, and other brain disorders; and epidemiological studies have shown that co-occurrence of neurodevelopmental and psychiatric disorders is the rule, rather than the exception, in affected individuals and within families. ASD, ID, SCZ, attention deficit/hyperactivity disorder (ADHD), epilepsy (EP), and bipolar disorder (BPD), for example, have long been conceptualized as clinically distinct entities but have overlapping symptoms, high rates of co-occurrence, etiologic heterogeneity, and shared risk factors; sometimes different disorders cluster within the same families [24•]. It has become increasingly clear that the genome does not respect psychiatry's clinical diagnostic boundaries; chromosomal microarray analysis (CMA) and whole exome sequencing (WES) studies have now detected many of the same pathogenic CNVs and SNVs across cohorts with different clinical presentations, as illustrated in Table 1 [27-36]. It has been proposed that neurodevelopmental and psychiatric diagnoses should not be viewed as causally and pathophysiologically distinct, but as the consequences of DBD, a common denominator that reflects altered neural development which can manifest clinically in diverse ways [24•, 37].

DBD represents a group of developmental, neurological, and psychiatric conditions characterized by cognitive, behavioral, language, motor, and other brain-based functional impairments [24•]. Rather than dichotomous, all-ornone disorders, ASD, ID, ADHD, SCZ, and other DBD are now thought to reflect varying degrees of dysfunction along a broad continuum of measurable (quantitative) human traits, including intelligence, social responsiveness, attention, language abilities, motor skills, and imaginative thought. All humans fall somewhere along the continuum of function for these quantitative traits, with diagnoses such as ASD representing the extreme end of a spectrum where function is impaired to the degree that it warrants a clinical label. Current opinions from top researchers in the field and by the US National Institutes of Mental Health suggest that ASD and other DBD can best be studied and conceptualized through quantitative behavioral and cognitive research, irrespective of artificially defined clinical diagnostic boundaries [23, 24•]. An important corollary is that DBD candidate gene discovery can be maximized by 
Table 1 Variable expressivity of the pathogenic recurrent copy number variants and single nucleotide variants most commonly identified in ASD cohorts

\begin{tabular}{|c|c|c|c|c|}
\hline & ASD & ID/DD & EP & SCZ \\
\hline \multicolumn{5}{|l|}{$\mathrm{CNV}$} \\
\hline 16p11.2 deletion & $X$ & $\mathrm{X}$ & $X$ & \\
\hline 16p11.2 duplication & $X$ & $\mathrm{X}$ & $X$ & $X$ \\
\hline 15q11.2-q13.1 (BP2-BP3) duplication & $X$ & $X$ & $X$ & $\mathrm{X}$ \\
\hline 15q13.2-q13.3 (BP4-BP5) deletion & $X$ & $\mathrm{X}$ & $X$ & $X$ \\
\hline 1q21.1 duplication & $X$ & $\mathrm{X}$ & $X$ & $X$ \\
\hline 22q11.2 duplication & $\mathrm{X}$ & $\mathrm{X}$ & $\mathrm{X}$ & \\
\hline $16 \mathrm{p} 13.11$ deletion & $X$ & $\mathrm{X}$ & $\mathrm{X}$ & $\mathrm{X}$ \\
\hline 7q11.23 duplication & $X$ & $\mathrm{X}$ & & $X$ \\
\hline $16 \mathrm{p} 12.2$ deletion & $\mathrm{X}$ & $\mathrm{X}$ & $X$ & $\mathrm{X}$ \\
\hline 17q12 deletion & $\mathrm{X}$ & $\mathrm{X}$ & $X$ & $\mathrm{X}$ \\
\hline \multicolumn{5}{|l|}{ SNV } \\
\hline NRXN1 & $\mathrm{X}$ & $X$ & $X$ & $X$ \\
\hline CTNNA3 & $X$ & $X$ & $X$ & $\mathrm{X}$ \\
\hline CHD8 & $X$ & $X$ & $X$ & $X$ \\
\hline$S C N 2 A$ & $X$ & $X$ & $X$ & \\
\hline$A D N P$ & $X$ & $X$ & $X$ & \\
\hline PTEN & $X$ & $X$ & $X$ & \\
\hline SCN1A & $X$ & $X$ & $X$ & \\
\hline SHANK3 & $X$ & $X$ & $X$ & $X$ \\
\hline$D Y R K 1 A$ & $X$ & $X$ & $X$ & \\
\hline$S Y N G A P 1$ & $X$ & $X$ & $X$ & $X$ \\
\hline
\end{tabular}

References [24•, 28, 33-36]

combining datasets from different neurodevelopmental and psychiatric disorders [28]. This changing conceptualization of autism and its interconnectedness with other DBD, and with the continuum of "normal" human behavior, has direct implications for pedigree interpretation, variant analysis, and risk assessment.

\section{Genetic Evaluation of ASD}

Children with autism and other neurodevelopmental concerns represent a significant percentage of referrals for clinical genetics evaluation, with etiological investigation being the primary indication. As in other areas of medical practice, genetic testing for individuals with ASD has moved beyond the purview of clinical genetics and is being ordered by developmental pediatricians, neurologists, psychiatrists, and other specialists, as well as by primary care providers. Pediatric genetic counselors therefore see children with ASD referred through a variety of portals and having undergone various degrees of genetic diagnostic work-up. Prenatal genetic counselors routinely field inquiries about ASD recurrence from expectant couples with a previous affected child, or more commonly, a family history of ASD. Within their growing specialty area, psychiatric genetic counselors increasingly encounter adults with mental illness who report autism symptoms in themselves and/or other family members. Additionally, a growing army of research and laboratory-based genetic counselors is employed on the front lines of variant interpretation for genes implicated in ASD. Thus, the impact of the theoretical "sea change" about ASD's connections to other neurodevelopmental disorders, and to adult-onset psychiatric conditions, has direct relevance across several different areas of genetic counseling practice.

Prior to the advent of array and whole genome/exome sequencing technologies, genetic contributors to ASD were largely unknown, and genetic counseling focused on empiric recurrence risks for ASD, occasionally informed by a positive pedigree. Consensus guidelines from national professional organizations, including the American College of Medical Genetics, the National Society of Genetic Counselors, and the American Academy of Pediatrics, recommend consideration of fragile $\mathrm{X}$ and CMA for children diagnosed with ASD [38-41], and increasingly, clinical WES is being ordered as a standard part of the etiological evaluation of neurodevelopmental disorders. Although specific genetic causes are individually rare in ASD, they collectively represent its most significant known etiology $[8,15 \cdot, 28,42]$. Whole genome CMA reveals a pathogenic CNV in 15-20\% of individuals with unexplained developmental delay, ID, ASD, or multiple congenital anomalies $[43,44]$. The reported yield is $7-14 \%$ in studies restricted to the evaluation of individuals with ASD [45-50]. Large laboratory-based clinical WES studies have consistently identified a pathogenic SNV in 26-29\% of people with neurodevelopmental disorders in general [51-53], including 8-20\% of those with ASD [50, 52, 53]. Among children with ASD who underwent both CMA and WES testing, the combined molecular diagnostic yield was $15.8 \%$ [50].

When a specific cause can be identified for ASD, genetic counseling has traditionally followed familiar processes with regard to risk assessment, explanations of inheritance, recommended family testing, anticipatory medical guidance, and discussion of psychosocial aspects of genetic disorders. For well-known genetic causes of ASD, such as fragile $\mathrm{X}$ syndrome, there may be an abundance of resources and established support organizations for the family. More commonly, however, little is known about the genetic diagnosis, as is the case for the large number of newly identified rare, pathogenic CNVs and SNVs implicated in autism. These include pathogenic microdeletions of $15 q 11.2$ and loss of function variants in NRXN1 that can cause ASD but also confer risk for a wide range of other neurodevelopmental and psychiatric diagnoses, from ID to SCZ, and are found as well in seemingly unaffected 
individuals $[34,36,50,51,54]$. With few exceptions, the phenotypic effects of this recent generation of CMA and WES-detected etiologies of autism are nonsyndromic, meaning that they do not induce structural organ defects, overt dysmorphic features, or significant medical comorbidities. For these newly identified causes, genetic counseling relies heavily on variant analysis and pedigree interpretation and requires a broader discussion of neurodevelopmental and psychiatric risk beyond a family's focused concern about autism. This represents a marked departure from the traditional model of genetic counseling in which ASD is described as one specific characteristic among a syndrome's physical and medical features [25•].

\section{The DBD Pedigree}

A hallmark of genetic counseling practice is the ability to construct a detailed family pedigree in order to inform genetic risk assessment. When a consistent physical trait is present, as in families with multigenerational cystic kidneys, for example, a pedigree serves as a visual shorthand that allows the genetic counselor to quickly deduce an inheritance pattern. For neurodevelopmental and psychiatric phenotypes, these patterns are not quite so straightforward and often obscured by artificial diagnostic distinctions, masking the true magnitude of DBD recurrence. In medical genetics, ASD, EP, BPD, cerebral palsy, and other DBD are still widely and incorrectly viewed as unrelated conditions, each one designated with its own distinct symbol or colored quadrant in a pedigree to emphasize their presumed lack of connection to each another [25•]. Likewise, recurrence estimates for ASD have historically been based on singleminded analyses of repeated instances of ASD (vs. no ASD) in families, despite the eagerness of parents to point out an uncle with obsessive compulsive disorder or a sibling with significant language impairment. Once dismissed as irrelevant, the importance of these seemingly unrelated diagnoses in other relatives is now being appreciated and forcing a reexamination of the long-held genetic tenets of nonpenetrance and variable expressivity, at least in terms of neuropsychiatric phenotypes [24•, 25•, 54].

Studies published in the last decade suggest that the empiric risk for recurrence of idiopathic ASD hovers around $10 \%$ (range $\sim 7$ to $14 \%$ ) for couples with one affected child [55-59, 60•], but may be as high as 32-36\% for couples who already have two or more children with idiopathic ASD [57, 61]. Only recently have studies begun to connect the dots between autism and different types of $\mathrm{DBD}$, and the recurrence risk for any type of $D B D$ in families with one ASD proband is far higher than previously imagined [60॰]. For example, in a large Finnish epidemiologic study involving thousands of families, the prevalence of ASD among siblings of probands with ASD was $10.5 \%$, but almost $37 \%$ of these siblings had some type of neurodevelopmental or psychiatric disorder (vs. $17.4 \%$ of controls) [60॰]. Specifically, the risk among siblings was significantly increased for tic disorder, ADHD, ID, learning or coordination disorder, conduct or oppositional disorder, childhood-onset emotional disorder, SCZ spectrum disorder, affective disorder, and anxiety disorder [60॰]. Recurrence risks for siblings were similar whether or not the proband had ID and irrespective of proband gender. Much smaller studies have suggested that $20-25 \%$ of siblings who do not meet criteria for ASD have a history of language impairment or delay [56, 62]. It is increasingly apparent that the traditional pedigree designating ASD, ID, and other DBD as distinct and unrelated conditions in a family is fundamentally flawed. Likewise, recurrence risk estimates that address only the isolated chance for ASD without referencing the significantly higher chance for other DBD can no longer be considered acceptable.

Families who seek genetic counseling about autism are generally unaware of its newly discovered cross-connections with other DBD. Traditionally, genetic counselors list ASD, along with a condition's other known physical and behavioral traits, and cite its relative chance of occurring as part of the disorder [25•]. While a syndrome's physical manifestations can be accurately described in an all-ornone, categorical way (e.g., 75 with vs. $25 \%$ without a congenital cardiac defect), the same is not true of behavioral and cognitive symptoms. For example, approximately $15 \%$ of children with a 22q11.2 deletion meet behavioral criteria for an ASD diagnosis [63]. A parent might easily assume that $85 \%$ of those with a 22q11.2 deletion are completely unaffected by ASD, not appreciating that autism symptoms occur along a continuum that extends beyond the black and white cutoff for a clinical ASD diagnosis. Describing the prevalence of a syndrome's neurodevelopmental and psychiatric diagnoses in the same breath as congenital anomalies is misleading and fails to convey the continuously distributed nature of brain-based symptoms. Whether the etiology is unknown, due to a welldefined syndrome, or associated with a poorly understood genomic variant, the recognition that ASD is etiologically tethered to a host of other brain disorders and to the continuum of "normal" human behavior is forcing a reexamination of genetic counseling approaches. So far, clinical genetics professionals have paid relatively little attention to the seismic changes occurring in the fields of psychiatry and developmental medicine that will ultimately have a major impact on how autism and other brain disorders are defined, described, and treated [5, 24•, 26, 64-66]. "Reinventing" genetic counseling practices related to these disorders will arguably be one of the most important challenges facing the profession over the coming decade. 


\section{Conclusions}

Psychiatry is steadily moving toward a new conceptualization of brain disorders that blurs long-held diagnostic distinctions among neurodevelopmental and psychiatric conditions, including autism. Genomic discoveries lie at the heart of these changing perceptions, yet there has so far been minimal impact on traditional genetic counseling practices that continue to view ASD through the lens of a categorical, all-or-none risk model. Going forward, the genetic counseling field will need to significantly adapt its approaches to pedigree interpretation, variant analysis, and patient education to more precisely describe both the chance and the nature of autism recurrence in terms of a broader DBD continuum. These efforts will have implications for multiple practice areas and require philosophical changes for experienced practitioners and for the training of new genetic counselors. Resetting entrenched dichotomous notions about autism, ID, and other brainbased manifestations of genetic conditions will require a strategic educational effort on the part of the genetic counseling profession. Once accomplished, families seeking genetic counseling will benefit from a more accurate and contextual understanding of these disorders on which to base informed decisions.

Acknowledgments This work was supported by the National Institute of Mental Health of the National Institutes of Health under award RO1MH074090. The content is solely the responsibility of the authors and does not necessarily represent the official views of the National Institutes of Health.

\section{Compliance with Ethical Guidelines}

Disclosure Brenda Finucane and Scott M. Myers declare that they have no conflict of interest.

Human and Animal Rights and Informed Consent This article does not contain any studies with human or animal subjects performed by any of the authors.

Open Access This article is distributed under the terms of the Creative Commons Attribution 4.0 International License (http:// creativecommons.org/licenses/by/4.0/), which permits unrestricted use, distribution, and reproduction in any medium, provided you give appropriate credit to the original author(s) and the source, provide a link to the Creative Commons license, and indicate if changes were made.

\section{References}

Recently published papers of particular interest have been highlighted as:

- Of importance

1. Mitchell KJ. Foreword. In: Mitchell KJ, editor. The genetics of neurodevelopmental disorders. Hoboken: Wiley; 2015.
2. Kanner L. Autistic disturbances of affective contact. Nerv Child. 1943;2:217-50.

3. - Baker JP. Autism at 70-redrawing the boundaries. N Engl J Med. 2013;369(12):1089-91. Article summarizes history of autism as a recognized psychiatric diagnosis and describes potential implications of current DSM-5 consensus criteria.

4. American Psychiatric Association. Diagnostic and statistical manual of mental disorders. 5th ed. Arlington: American Psychiatric Association; 2013.

5. Volkmar FR, McPartland JC. From Kanner to DSM-5: autism as an evolving diagnostic concept. Annu Rev Clin Psychol. 2014;10:193-212.

6. Tick B, Bolton P, Happé F, Rutter M, Rijsdijk F. Heritability of autism spectrum disorders: a meta-analysis of twin studies. J Child Psychol Psychiatry. 2016;57(5):585-95.

7. Bourgeron $T$. From the genetic architecture to synaptic plasticity in autism spectrum disorder. Nat Rev Neurosci. 2015;16: 551-63.

8. De Rubeis S, Buxbaum JD. Genetics and genomics of autism spectrum disorder: embracing complexity. Hum Mol Genet. 2015;24:R24-31.

9. Gaugler T, Klei L, Sanders SJ, Bodea CA, Goldberg AP, Lee AB, et al. Most genetic risk for autism resides with common variation. Nat Genet. 2014;46:881-5.

10. Pinto D, Delaby E, Merico D, Barbosa M, Merikangas A, Klei L, et al. Convergence of genes and cellular pathways dysregulated in autism spectrum disorders. Am J Hum Genet. 2014;94(5):67794. doi:10.1016/j.ajhg.2014.03.018.

11. De Rubeis S, He X, Goldberg AP, Poultney CS, Samocha K, Cicek AE. Synaptic, transcriptional, and chromatin genes disrupted in autism. Nature. 2014;515:209-15.

12. Jacquemont S, Coe BP, Hersch M, Duyzend MH, Krumm N, Bergmann $S$, et al. A higher mutational burden in females supports a "female protective model" in neurodevelopmental disorders. Am J Hum Genet. 2014;94:415-25.

13. Gockley J, Willsey AJ, Dong S, Dougherty JD, Constantino JN, Sanders SJ. The female protective effect in autism spectrum disorder is not mediated by a single genetic locus. Mol Autism. 2015;6(25):1-10. doi:10.1186/s13229-015-0014-3.

14. Desachy G, Croen LA, Torres AR, Kharrazi M, Delorenze GN, Windham GC, et al. Increased female autosomal burden of rare copy number variants in human populations and in autism families. Mol Psychiatry. 2015;20:170-5.

15. - Sanders SJ, He X, Willsey J, Ercan-Sencicek AG, Samocha KE, Cicek AE, et al. Insights into autism spectrum disorder genetic architecture and biology from 71 risk loci. Neuron 2015;87: 1215-33. Study analyzed de novo CNVs and exome sequencing data from large scale Autism Consortia to identify 71 ASD risk loci, including $6 \mathrm{CNV}$ regions and 65 risk genes.

16. Christensen DL, Baio J, Braun KV, et al. Prevalence and characteristics of autism spectrum disorder among children aged 8 years-autism and developmental disabilities monitoring network, 11 sites, United States, 2012. MMWR Surveill Summ. 2016;65(No. SS-3):1-23.

17. Nassar N, Dixon G, Bourke J, Bower C, Glasson E, de Klerk N, Leonard H. Autism spectrum disorders in young children: effect of changes in diagnostic practices. Int J Epidemiol. 2009;38(5): $1245-54$.

18. Rice CE, Rosanoff M, Dawson G, Durkin MS, Croen LA, Singer A, Yeargin-Allsopp M. Evaluating changes in the prevalence of the autism spectrum disorders (ASDs). Public Health Rev. 2013;34(2):1-22.

19. Hansen SN, Schendel DE, Parner ET. Explaining the increase in the prevalence of autism spectrum disorders: the proportion attributable to changes in reporting practices. JAMA Pediatr. 2015;169(1):56-62. 
20. Polyak A, Kubina RM, Girirajan S. Comorbidity of intellectual disability confounds ascertainment of autism: implications for genetic diagnosis. Am J Med Genet B Neuropsychiatr Genet. 2015;168(7):600-8.

21. Bishop DVM, Whitehouse AJO, Watt HJ, Line EA. Autism and diagnostic substitution: evidence from a study of adults with a history of developmental language disorder. Dev Med Child Neurol. 2008;50:341-5.

22. Coo H, Ouellette-Kuntz H, Lloyd JEV, Kasmara L, Holden JJA, Lewis MES. Trends in autism prevalence: diagnostic substitution revisited. J Autism Dev Disord. 2008;38(6):1036-46.

23. Insel $\mathrm{T}$, Cuthbert $\mathrm{B}$, Garvey $\mathrm{M}$, et al. Research domain criteria (RDoC): toward a new classification framework for research on mental disorders. Am J Psychiatry. 2010;167(7):748-51. doi:10. 1176/appi.ajp.2010.09091379.

24. - Moreno-De-Luca A, Myers SM, Challman TD, Moreno-DeLuca D, Evans DW, Ledbetter DH. Developmental brain dysfunction: revival and expansion of old concepts based on new genetic evidence. Lancet Neurol. 2013;12:406-14. Article provides historical context and detailed conceptual framework for developmental brain dysfunction.

25. - Finucane B, Challman TD, Martin CL, Ledbetter DH. Shift happens: family background influences clinical variability in genetic neurodevelopmental disorders. Genet Med. 2016;18(4): 302-4. doi:10.1038/gim.2015.92. Commentary describes potential future applications of using quantitative traits to refine prognosis for genetic neurodevelopmental disorders.

26. Owen MJ. New approaches to psychiatric diagnostic classification. Neuron. 2014;84(3):564-71.

27. Coe BP, Girirajan S, Eichler EE. The genetic variability and commonality of neurodevelopmental disease. Am J Med Genet C. 2012;160C:118-29.

28. Gonzalez-Mantilla AJ, Moreno-De-Luca A, Ledbetter DH, Martin CL. A cross-disorder method to identify novel candidate genes for developmental brain disorders. JAMA Psychiatry 2016;73(3):275-83 and associated DBD gene database. http:// geisingeradmi.org/care-innovation/studies/dbd-genes/. Accessed 10 June 2016.

29. Malhotra D, Sebat J. CNVs: harbingers of a rare variant revolution in psychiatric genetics. Cell. 2012;148:1223-41.

30. Sebat J, Levy DL, McCarthy SE. Rare structural variants in schizophrenia: one disorder, multiple mutations; one mutation, multiple disorders. Trends Genet. 2009;25(12):528-35. doi:10. 1016/j.tig.2009.10.004.

31. Pescosolido MF, Gamsiz ED, Nagpal S, Morrow EM. Distribution of disease-associated copy number variants across distinct disorders of cognitive development. J Am Acad Child Adolesc Psychiatry. 2013;52:414-30.

32. Li J, Cai T, Jiang Y, Chen H, He X, Chen C, et al. Genes with de novo mutations are shared by four neuropsychiatric disorders discovered from NPdenovo database. Mol Psychiatry. 2016;21: $290-7$.

33. Moreno-De-Luca D, Sanders SJ, Willsey AJ, Mulle JG, Lowe JK, Geschwind $\mathrm{DH}$, et al. Using large clinical data sets to infer pathogenicity for rare copy number variants in autism cohorts. Mol Psychiatry. 2013;18:1090-5.

34. Kirov G. CNVs in neuropsychiatric disorders. Hum Mol Genet. 2015;24:R45-9.

35. Mefford HC. CNVs in epilepsy. Curr Genet Med Rep. 2014;2(3): 162-7. doi:10.1007/s40142-014-0046-6.

36. Torres F, Barbosa M, Maciel P. Recurrent copy number variations as risk factors for neurodevelopmental disorders: critical overview and analysis of clinical implications. J Med Genet. 2016;53(2):73-90. doi:10.1136/jmedgenet-2015-103366 (Epub 26 Oct 2015).
37. Myers SM. Diagnosing developmental disabilities. In: Batshaw ML, Roizen NJ, Lotrecchiano GR, editors. Children with disabilities. 7th ed. Baltimore: Brookes; 2013. p. 243-66.

38. Johnson CP, Myers SM, American Academy of Pediatrics Council on Children with Disabilities. Identification and evaluation of children with autism spectrum disorders. Pediatrics. 2007;120:1183-206.

39. Manning M, Hudgins L. Array-based technology and recommendations for utilization in medical genetics practice for detection of chromosomal abnormalities. Genet Med. 2010;12: $742-5$.

40. Schaefer GB, Mendelsohn NJ, Professional Practice and Guidelines Committee. Clinical genetics evaluation in identifying the etiology of autism spectrum disorders: 2013 guideline revisions. Genet Med. 2013;2013(15):399-407.

41. Finucane B, Abrams L, Cronister A, Archibald AD, Bennett RL, McConkie-Rosell A. Genetic counseling and testing for FMRI gene mutations: practice Guidelines of the National Society of Genetic Counselors. J Genet Couns. 2012;21(6):752-60.

42. Krumm N, O’Roak BJ, Shendure J, Eichler EE. A de novo convergence of autism genetics and molecular neuroscience. Trends Neurosci. 2014;37:95-105.

43. Miller DT, Adam MP, Aradhya S, Biesecker LG, Brothman AR, Carter NP, et al. Consensus statement: chromosomal microarray is a first-tier clinical diagnostic test for individuals with developmental disabilities or congenital anomalies. Am J Hum Genet. 2010;86:749-64.

44. Hochstenbach R, Buizer-Voskamp JE, Vorstman JA, Ophoff RA. Genome arrays for the detection of copy number variations in idiopathic mental retardation, idiopathic generalized epilepsy and neuropsychiatric disorders: lessons for diagnostic workflow and research. Cytogenet Genome Res. 2011;135:174-202.

45. Shen Y, Dies KA, Holm IA, Bridgemohan C, Sobeih MM, Caronna EB, et al. Clinical genetic testing for patients with autism spectrum disorders. Pediatrics. 2010;125:e727-35.

46. Battaglia A, Doccini V, Berardini L, Novelli A, Loddo S, Capalbo A, Filippi T, Carey JC. Confirmation of chromosomal microarray as a first-tier clinical diagnostic test for individuals with developmental delay, intellectual disability, autism spectrum disorders, and dysmorphic features. Eur J Pediatr Neurol. 2013; 17:589-99.

47. McGrew SG, Peters BR, Crittendon JA, Veenstra-Vanderweele J. Diagnostic yield of chromosomal microarray analysis in an autism primary care practice: Which guidelines to implement? J Autism Dev Disord. 2012;42:1582-91.

48. Roberts JL, Hovanes K, Dasouki M, Manzardo AM, Butler MG. Chromosomal microarray analysis of consecutive individuals with autism spectrum disorders or learning disability presenting for genetic services. Gene. 2014;535:70-8.

49. Eriksson MA, Lieden A, Westerlund J, Bremer A, Wincent J, Sahlin E, et al. Rare copy number variants are common in young children with autism spectrum disorder. Acta Paediatr. 2015;104: $610-8$.

50. Tammimies K, Marshall CR, Walker S, Kaur G, Thiruvahindrapuram B, Lionel AC, et al. Molecular diagnostic yield of chromosomal microarray analysis and whole-exome sequencing in children with autism spectrum disorder. JAMA. 2015;214:895-903.

51. Yang Y, Muzny DM, Xia F, Niu Z, Person R, Ding Y, et al. Molecular findings among patients referred for clinical wholeexome sequencing. JAMA. 2014;312:1870-9.

52. Lee H, Deignan JL, Dorrani N, Strom SP, Kantarci S, QuinteroRivera $\mathrm{F}$, et al. Clinical exome sequencing for genetic identification of rare Mendelian disorders. JAMA. 2014;312:1880-7.

53. Retterer K, Juusola J, Cho MT, Vitakaza P, Millan F, Gibellini F, et al. Clinical application of whole-exome sequencing across 
clinical indications. Genet Med. 2015. doi:10.1038/gim.2015.148 (Epub ahead of print).

54. Moreno-De-Luca A, Evans DW, Ledbetter DH, et al. The role of parental cognitive, behavioral, and motor profiles in clinical variability in individuals with chromosome 16p11.2 deletions. JAMA Psychiatry. 2015;72(2):119-26.

55. Sumi S, Taniai H, Miyachi T, Tanemura M. Sibling risk of pervasive developmental disorder estimated by means of an epidemiologic survey in Nagoya, Japan. J Hum Genet. 2006;51: 518-22.

56. Constantino JN, Zhang Y, Frazier T, Abbacchi AM, Law P. Sibling recurrence and the genetic epidemiology of autism. Am J Psychiatry. 2010;167:1349-56.

57. Ozonoff S, Young GS, Carter A, Messinger D, Yirmiya N, Zwaigenbaum L, et al. Recurrence risk for autism spectrum disorders: a Baby Siblings Research Consortium study. Pediatrics. 2011;128:e488-95.

58. Sandin S, Lichtenstein P, Kuja-Halkola R, Larsson H, Hultman CM, Reichenberg A. The familial risk of autism. JAMA. 2014;311:1770-7.

59. Gronborg TK, Schendel DE, Parner ET. Recurrence of autism spectrum disorders in full- and half-siblings and trends over time: a population-based cohort study. JAMA Pediatr. 2013;2259:E17. doi:10.1001/jamapediatrics.2013.2259.

60. - Jokiranta-Olkoniemi E, Cheslack-Postava K, Sucksdorff D, Suominen A, Gyllenberg D, Chudal R, et al. Risk of psychiatric and neurodevelopmental disorders among siblings of probands with autism spectrum disorders. JAMA Psychiatry 2016;73(6): 622-9. doi:10.1001/jamapsychiatry.2016.0495. Large Finnish study of over 3500 families examined recurrence risks for autism and other brain disorders among siblings of probands with ASD.

61. Werling DM, Geschwind DH. Recurrence rates provide evidence for sex-differential, familial genetic liability for autism spectrum disorders in multiplex families and twins. Mol Autism. 2015;6:27. doi:10.1186/s13229-015-0004-5.

62. Lindgren KA, Folstein SE, Tomblin JB, Tager-Flusberg H. Language and reading abilities of children with autism spectrum disorders and specific language impairment and their first degree relatives. Autism Res. 2009;2:22-38.

63. Schneider M, Debbané M, Bassett AS, Chow EWC, Fung WLA, Van den Bree MBM. Psychiatric disorders from childhood to adulthood in 22q11.2 deletion syndrome: results from the International Consortium on Brain and Behavior in 22q11.2 Deletion Syndrome. Am J Psychiatry. 2014;171(6):627-39. doi:10.1176/ appi.ajp.2013.13070864.

64. Buxbaum JD. DSM-5 and psychiatric genetics-round hole, meet square peg. Biol Psychiatry. 2015;77:766-8.

65. Stessman HA, Turner TN, Eichler EE. Molecular subtyping and improved treatment of neurodevelopmental disease. Genome Med. 2016;8(1):22.

66. Insel T, Cuthbert BN. Brain disorders? Precisely. Precision medicine comes to psychiatry. Science. 2015;348(6234): 499-500. doi:10.1126/science.aab2358. 